\title{
Prioritizing Intelligence in Conducting Football Training
}

\author{
Ahmad Chaeroni*, Nurlan Kusmaedi \\ Sport Education Program \\ Faculty of Sport Education and Health \\ Universitas Pendidikan Indonesia \\ Bandung, Indonesia \\ *ahchaer@upi.edu
}

\author{
Andre Igoresky \\ Sport Education Program \\ Faculty of Sport Education and Health \\ Universitas Negeri Padang \\ Padang, Indonesia
}

\begin{abstract}
The training program used by SSB ASCO did not pay attention to the intelligence aspects so that it had not been able to speak much in football matches in the city of Padang. This study aims to find out whether there is a relationship between the level of intelligence and basic techniques of football in SSB ASCO students. This research is a correlational study, with a sample of 28 students. The data analysis technique uses Pearson correlation formula. From the data analysis shows that students who have intelligence above the average have a good basic football technique. Whereas students who have low intelligence have the basic techniques of football below. Thus the level of intelligence influences students' basic football techniques. Therefore, in conducting soccer coaching it is necessary to prioritize the level of intelligence of students in order to produce good football players.
\end{abstract}

Keywords—intelligence; coaching and football

\section{INTRODUCTION}

The soccer school (SSB) is a place for children to learn more about football. The football school not only provides a way to develop football, but soccer schools are also able to reform the football sports training system [1]. Soccer practice is not only aimed at forming expertise but also to increase knowledge, because intelligence supports expertise [2], in addition, cognitive censorship of an athlete is faster than that of non-athletes [3], in superior cognitive processes must improve the process of maintaining the response used in decision making [4], likewise, the quality of intelligence is the main determinant of the success of an athlete [5].

The results of the study prove that, someone who uses emotional information to help in making decisions [6], emotional levels are highlighted as a stable disposition related to sports performance [7], intelligence is also the most advanced conceptualization in understanding the characteristics of emotional traits [8], intelligence will help in higher decision making related to athletes' abilities [9], physical movement characteristics according to increased brain activity [10]. However, at the level of certain athletes (beginner athletes) compared to non-athletes, the level of intelligence is lower than that of non-athletes [11]. Identification and development of talent in football is a multi-functional approach that involves systematic assessment of the physiological, technical, tactical, social and psychological characteristics of the player [12], skill is an action or task that is done intentionally to achieve a certain goal [13]

So far, researcher have not found the SSB (specifically at SSB ASCO) in the city of Padang which emphasizes the development of intelligence capabilities in their students.This can be seen when playing, which is the mastery of passing techniques are often less accurate, when dribbling quickly taken by the opponent, and other skills are also still very low. Therefore researchers feel the need to research related intelligence in conducting soccer coaching on the SSB. the findings in this study will answer questions about: Is there a relationship between the level of intelligence and basic techniques of football in SSB ASCOstudents?

\section{RESEARCH METHODOLOGY}

This study is a correlational study, which is to find out whether there is a relationship between intelligence and the basic techniques of playing football on SSB ASCO children. The sampling technique in this study uses a total sampling technique, which determines the sample based on the existing population. Thus the number of samples in this study is as much as the population that exists, namely 28 ASCO Padang Sarai football school students in Padang city.

To determine the level of intelligence of children, researchers conducted tests with IQ. Whereas to see the basic techniques of the child the researchers conducted a test of basic soccer skills. Furthermore, to analyze the data researchers used Pearson correlation formula.

\section{RESULTS}

The data produced in this study were processed using the formula of person correlation. But before it is processed with the person correlation formula, first the data of the basic football ability tests (wall volley, dribbling, arrival pass for, and ball control), are processed using the t-score formula, after the t-score data is obtained then the rats are searched As a result, this is the score test of basic football technical skills, and then correlated with the IQ ability test data using the formula of person correlation. From the results of the data analysis proves 
that, students have a high level of intelligence have high basic technical skills as well.

TABLE I. DATA CORRELATION

\begin{tabular}{|c|c|l|l|}
\hline \multicolumn{2}{|c|}{} & \multicolumn{1}{|c|}{ IQ } & \multicolumn{1}{c|}{$\begin{array}{c}\text { Basic } \\
\text { Football } \\
\text { Skills }\end{array}$} \\
\hline \multirow{3}{*}{ IQ } & Pearson Correlation & 1 & $.782^{* *}$ \\
\cline { 2 - 4 } & Sig. (2-tailed) & & 000 \\
\cline { 2 - 4 } & $\boldsymbol{N}$ & 28 & 28 \\
\hline \multirow{3}{*}{$\begin{array}{c}\text { Basic Football } \\
\text { Skills }\end{array}$} & Pearson Correlation & $.782^{* *}$ & 1 \\
\cline { 2 - 4 } & Sig. (2-tailed) & .000 & \\
\cline { 2 - 4 } & $\boldsymbol{N}$ & 28 & 28 \\
\hline
\end{tabular}

Based on the results of the calculation using the formula person correlation obtained the result of $r$ count is greater than $r$ table $(0.782>0.374)$, with a significance of 0.000 it can be concluded that IQ has a strong correlation with the basic abilities in football games. Therefore, from the data analysis of 28 students, students who have intelligence above average have good basic football techniques. Whereas those with low intelligence have an effect on the low level of basic football techniques. Thus the level of intelligence has a close relationship with both the bad and basic techniques of student football. So in conducting football coaching it is necessary to prioritize the level of intelligence of students above average in order to produce good football players.

\section{DISCUSSION}

The take-home message is that perceptual cognitive skills of players can receive training and instruction and, consequently, an important challenge for trainers is to determine the best way to design, implement and evaluate appropriate training programs and practices [14]. One last question remains; How do coaches know that players know and understand what game intelligence is? One obvious answer is kinesthetic where the trainer observes the player who executes or replicates the game's intelligence skills, or its components, in training and in competitive matches. However, one major problem when designing practical activities involves' retention and transfer of learning from the activity to the complexity of field performance [15]. We know that possession of superior perceptual cognitive skills is a function of the task-specific knowledge base that is enhanced by players developed through experience, quality of training, and coaching instructions. In addition, involvement in soccer-specific training activities during adolescence and certain sports playing activities during childhood especially are factors that contribute to the development of perceptual cognitive skills [16]. In this case, a lot of evidence supports how small games that involve gamespecific contexts and situations facilitate the development of player awareness (eg play patterns, spatial recognition) and problem-solving abilities that often help players to make faster, more efficient. decision during the match [17]. We also know that Teaching Games are for Understanding [18]. guided discovery [19], learning through understanding [20]. and it is inseparable from the intelligence abilities of students to be able to receive quickly and cerman as much as the knowledge transferred by the coach. This is evident from the results of research, that the level of intelligence will greatly affect the level of basic technical skills of [21].

convincing empirical evidence now exists to show that anticipation and decision-making skills, the underlying game intelligence, can receive training, practice, and appropriate instructions and can be obtained and developed using appropriate interventions and testing mechanisms [22]. Athletes have a higher level of decision making than nonathletes [23], may also indicate a more effective decisionmaking strategy outside of sports [24], the results of research have shown that elite athletes are more successful in making decisions from actions, certainly in their own sports when compared with non athletes [25], or in other words, elite athletes are able to simplify decision-making strategies which are one strategy of certain sports [26].

Compared to anthropometric and physiological skills, cognitive skills are considered to have more influence on success in playing football and especially at the elite level [27], the perception of cognitive skills, is often considered by the coach as knowledge about play or play intelligence, which combines the ability to play to read games, anticipate opponents and involve key skills such as creativity, innovation, and decision making [28]. Cognitive ability also refers to the ability to think of strategies that actively assist and modify actions during the game, which facilitates expectations about what will happen in certain circumstances [29], this decision often occurs when under pressure, where the opposing player tries to limit space and time. Perceptions of cognitive skills combine a number of key components or cognitive factors, such as increasing knowledge about situational problems, recognizing playing patterns, utilizing visual strategies and processing conspective information [30].

\section{CONCLUSION}

Basic techniques of football will be easily mastered if the person digests the material presented by the coach. The purpose of this research is to find out how big the relationship is to mastering the basic techniques of football in football school students. This study reports data on basic football techniques based on intelligence on ASCO soccer schools, Padang, West Sumatra. Analysis of data on 28 students showed that students who had intelligence above average had good basic football techniques. Whereas those with low intelligence have an effect on the low level of basic football techniques. Thus the level of intelligence has a close relationship with both the bad and basic techniques of student football. So in conducting football coaching it is necessary to prioritize the level of intelligence of students above average in order to produce good football players.

\section{REFERENCES}

[1] T. Liu, Z. Mao, and P. Zha, "School football: the new hope! Exploring the new nationwide system of Chinese sport," Asia Pacific Journal of Sport and Social Science, vol. 132, pp. 2164-2199, 2016.

[2] S. Laborde, F. Dosseville, and M. Raab, "Introduction, comprehensive approach, and vision for the future. Emotions and decision making in 
sports," International Journal of Sport \& Exercise Psychology, vol. 11, pp. 143-150, 2013.

[3] S. Mori, Y. Ohtani, and K. Imanaka, "Reaction times and anticipatory skills of karate athletes," Human Movement Science, vol. 21, pp. 213230, 2002

[4] H. Nakamoto, and S. Mori, "Sport-specific decision making in a Go/Nogo reaction task: Difference among nonathletes and baseball and basketball players," Perceptual and Motor Skills, vol. 106, pp. 163-170, 2008

[5] M. Raab, and J.G. Johnson, "Individual differencesof action orientation for risk-taking in sports," Research Quarterly for Exercise and Sport, vol. 75, no. (3), pp. 326-336, 2004.

[6] A. Panno, M.A. Donati, F. Chiesi, and C. Primi, "Trait emotional intelligence is related to risk-taking through negative mood and anticipated fear," Journal of Personality and Social Psychology, vol. 46, pp. 361-367, 2015.

[7] M.S. Allen, and S. Laborde, "Theroleofpersonalityinsport and physical activity," Current Directions in Psychological Science, vol. 23, pp. 460465, 2014.

[8] K.V. Petrides, R. Pita, and F. Kokkinaki, "The location of trait emotional intelligence in personality factor space," British Journal of Psychology, vol. 98, pp. 273-289, 2007.

[9] R. Vaughan, S. Laborde, and C. Mcconville, "The effect of athletic expertise and trait emotional intelligence on decision-making," European Journal of Sport Science, vol. 8, pp. 1536-1572, 2007.

[10] Y.J. Kima, E.J. Chab, K.D. Kangc, B.-N. Kimd, and D.H. Hane, "The effects of sport dance on brain connectivity and body intelligence," Journal of cognitive psychology, vol. 6, pp. 2044-5911, 2016.

[11] H.S. Slusher, "Personality and Intelligence Characteristics of Selected High School Athletes and Non,athletes," vol. 35, no. 4, pp. 539-545, 2015

[12] A.M. Williams, P.R. Ford, D.W. Eccles, and P. Ward, "PerceptualCognitive expertise in sport and its acquisition: Implications for applied cognitive psychology," Applied Cognitive Psychology, vol. 25, pp. 432442, 2010.

[13] R.A. Magill, Motor learning Concepts and Applications. Boulevard: Wm. C. Brown Communications, Inc., 1995.

[14] E.J. Pedhazur, Multiple Regression in Behavoral Research. New York: Holt, Rinehart \& Winston, 1982

[15] A.M. Williams, and N.J. Hodges, "Practice, Instruction and Skill Acquisition in Soccer: Challenging Tradition," Journal of Sports Sciences, vol. 23, no. 6, pp. 637-650, 2005.

[16] D.P. Broadbent, J. Causer, A.M. Williams, and P.R. Ford, "Perceptualcognitive Skill Training and Its Transfer to Expert Performance in the Field: Future Research Directions," European Journal of Sport Science, vol. 15 , no. 4, pp. 322-331, 2015.
[17] A. Roca, A.M. Williams, and P.R. Ford. "Developmental Activities and the Acquisition of Superior Anticipation and Decision Making in Soccer Players," Journal of Sports Sciences, vol. 30, no. 15, pp. 1643-1652, 2012

[18] K. Davids, D. Araújo, V. Correia, and L. Vilar, "How Small-Sided and Conditioned Games Enhance Acquisition of Movement and DecisionMaking Skills," Exercise and Sport Sciences Reviews, vol. 41, no. 3, pp. 154-161, 2013.

[19] R.L. Light, S. Harvey, and A Mouchet, "Improving 'At-action' Decisionmaking in Team Sports through a Holistic Coaching Approach," Sport, Education and Society, vol. 19, no. 3, pp. 258-275, 2014

[20] T.G. Cassidy, R.L. Jones, and P. Potrac, Understanding Sports Coaching: The Pedagogical, Social and Cultural Foundations of Coaching Practice. London: Routledge, 2015.

[21] D. Hauw, "The Predictive Ability of the Talent Development Environment on Youth Elite Football Players' Well-being: A PersonCentered Approach," Reflective Practice, vol. 10, no. 3, pp. 341-352, 2009

[22] A.M. Williams, and N.J. Hodges, "Practice, Instruction and Skill Acquisition in Soccer: Challenging Tradition," Journal of Sports Sciences, vol. 23, no. 6, pp. 637-650, 2005.

[23] S. Laborde, F. Dosseville, and M. Raab, "Introduction, comprehensive approach, and vision for the future. Emotions and decision making in sports," International Journal of Sport \& Exercise Psychology, vol. 11, pp. 143-150, 2013.

[24] T.J. Gabbet, J. Carius, and M. Mulvey, "Does improved decision making ability reduce the psychological demands of game based activities in field sport athletes?" Journal of Strength and Conditioning Research, vol. 22, no. (6), pp. 2027-2035, 2008.

[25] B. Travassos, D. Araujo, K. Davids, K. O'Hara, J. Leitao, and A. Cortinhas, "Expertise effects on decision-making in sport are constrained by requisite response behaviours - A meta-analysis," Psychology of Sport and Exercise, vol. 14, no. (2), pp. 211-219, 2013.

[26] M. Raab, "Simple heuristics in sports," International Review of Sport and Exercise Psychology, vol. 5, pp. 104-120, 2012.

[27] A.M. Williams, and T. Reilly. "Talent Identification and Development in Soccer," Journal of Sports Sciences, vol. 18, no. 9, pp. 657-667, 2000.

[28] A. Roca, A.M. Williams, and P.R. Ford, "Developmental Activities and the Acquisition of Superior Anticipation and Decision Making in Soccer Players," Journal of Sports Sciences, vol. 30, no. 15, pp. 1643-1652, 2012.

[29] A.M. Williams, Science and Soccer: Developing Elite Performers. London: Routledge, 2013

[30] A.M. Williams, and T. Reilly, "Talent Identification and Development in Soccer," Journal of Sports Sciences, vol. 18, no. 9, pp. 657-667, 2000. 